\title{
Una espiritualidad no religiosa desde de la tradición cristiana
}

\author{
Uma espiritualidade não religiosa a partir da tradição cristã \\ A non-religious spirituality from a Christian tradition
}

Marià Corbí

\begin{abstract}
Resumen
Los tránsitos rápidos en los modos de sobrevivir las sociedades humanas, pasando en poco tiempo de sociedades preindustriales a industriales o de industriales a sociedades conocimiento innovación y cambio continuo, nos están exigiendo la posibilidad de una espiritualidad no ligada a creencias y no religiosa. No es necesario acudir a las tradiciones espirituales orientales, Budismo, Yoga, Vedanta Advaita, para poder presentar y vivir la posibilidad de una espiritualidad no religiosa; también desde el seno de la tradición cristiana podemos encontrar autores que posibilitan una espiritualidad no religiosa. Podemos apoyarnos en una importante noción de Nicolás de Cusa para intentarlo: el "no otro" como la dimensión absoluta de toda realidad. El Cusano considera que ese término es más adecuado para hablar de Eso absoluto de toda realidad, que el término Dios. Resulta también muy conveniente para vivir una espiritualidad que no divida la realidad en dos pisos: el mundano y el divino, el relativo y el absoluto, este mundo y el otro.
\end{abstract}

Palabras-clave: "no otro"; dimensión absoluta de lo real; dimensión relativa; espiritualidad no religiosa; sociedad de conocimiento.

\section{Resumo}

Mudanças rápidas nos modos de sobreviver nas sociedades humanas, passando rapidamente de sociedades préindustriais para industriais ou de industriais para sociedades de conhecimento, inovação e mudança constante, estamos reinvidicando a possibilidade de uma espiritualidade não vinculada a crenças e não religiosa. Não há necessidade de ir às tradições espirituais orientais, Budismo, Yoga, Advaita Vedanta, para apresentar e viver a possibilidade de uma espiritualidade não religiosa; também de dentro da tradição cristã, encontramos autores que permitem uma espiritualidade não religiosa. Podemos contar com uma noção importante de Nicolau de Cusa: o "Nãooutro", como a dimensão absoluta de toda a realidade. O Cusano considera que esse termo é mais apropriado falar desse absoluto de toda a realidade, que o termo Deus. É também muito conveniente para viver uma espiritualidade que não divide a realidade em dois pólos: o mundano eo divino, o relativo e absoluto, neste mundo e no próximo.

Palavras-chave: não-outro; dimensão absoluta do real; dimensão relativa; espiritualidade não religiosa; sociedade do conhecimento.

\begin{abstract}
Rapid changes in the ways of survival in human societies, passing quickly from pre-industrial to industrial societies or industrial societies to knowledge societies, characterized by innovation and constant change, require a kind of a non religious spirituality not tied to beliefs. No need to go to Eastern spiritual traditions, Buddhism, Yoga or Advaita Vedanta to show and experience the possibility of a non-religious spirituality; also within the Christian tradition, we find authors that allow non-religious spirituality. We can count on an important notion of Nicholas of Cusa: The "No-Other" as the absolute dimension of all reality. The Cusano considers that this term is more appropriate to describe that absolute of all reality then the term God. It is also very convenient to live a spirituality that does not divide reality into two poles: the mundane and the divine, the relative and absolute in this world and the next.
\end{abstract}

Keywords: 'not other'; the absolute dimension of the real; relative dimensión; non-religious spirituality; knowledge society.

Artigo recebido em 16 de junho de 2014 e aprovado em 22 de setembro de 2014.

* Doutor em Filosofia. Professor da Fundación Vidal y Barraquer ,e no Instituto de Teología Fundamental de Barcelona. País de origem: Espanha. E-mail: mcorbi@cetr.net. 


\section{Introducción}

En la situación cultural de un grupo amplio de países, que va invadiendo, de una forma $\mathrm{u}$ otra a todos los pueblos, la posibilidad de una espiritualidad no religiosa debe de ser una cuestión claramente explicitada y aceptada. Es probable que a medio y largo plazo sea esa la única posibilidad, en la medida que todos los colectivos humanos se vayan incorporando a las condiciones culturales de sociedades que ya disponen de potentes ciencias y tecnologías, en continuo y rápido crecimiento, con todo lo que eso supone de creación continua de nuevos productos y servicios que alteran las condiciones de vida de los pueblos.

Podríamos decir que la cultura humana, en general, ha entrado ya en las sociedades de conocimiento innovación y cambio constate. La posibilidad de que los humanos vivamos de la creación continua de conocimientos, está aquí ya, y ha llegado para quedarse. Las ventajas que ese modo de sobrevivencia ofrece a nuestra especie se han convertido, para esas nuevas sociedades industriales y para la humanidad entera, en algo semejante a un destino inevitable y sin posible vuelta atrás.

Para unos seres frágiles y necesitados como nosotros, lo que nos ofrece satisfacer mejor nuestras necesidades y nos proporciona mayor seguridad, se asume inevitablemente y se convierte, de hecho, en un destino que hay que asumir. Así paso con el tránsito de la caza-recolección a la agricultura, de la agricultura primitiva a la agricultura de riego organizada en grandes unidades jerarquizadas, o a la ganadería, o a las sociedades industriales, o a las sociedades de conocimiento, llamadas de conocimiento porque viven y prosperan de la creación continua de ciencias y tecnologías con las que obtienen continuos nuevos productos y nuevos servicios y no porque sean sociedades sabias.

Podríamos decir que en cuanto las sociedades de conocimiento se asientan y se implantan em la historia humana, se convierten, de hecho, em un destino inevitable, tarde o temprano, para todos los pueblos de la tierra. 


\section{La posibilidad de una espiritualidad no religiosa}

Vamos a ver brevemente qué suponen esas culturas de conocimiento que nos llevan a sostener que hay que explicitar y plantear prácticamente la posibilidad, para muchos ya la única posibilidad, de una espiritualidad no religiosa.

Continuaremos utilizando el término "espiritualidad" para entendernos mejor de qué estamos hablando, pero sería bueno ir sustituyendo ese término, que es propio de una antropología de "cuerpo/espíritu”, que ya no es la antropología de la gran mayoría de los pueblos que han salido de las culturas preindustriales. Sería más adecuado llamar "cualidad humana" y "cualidad humana profunda" para hablar del legado de sabiduría de nuestros antepasados.

La llamada “espiritualidad” es una cualidad intrínseca de nuestra condición de vivientes constituidos, como tales vivientes, por el habla.

Las sociedades de conocimiento se caracterizan por la creación constante y acelerada ciencias y tecnologías. Las ciencias aceleran el crecimiento de las tecnologías y las tecnologías contribuyen eficazmente a la aceleración del crecimiento de las ciencias. Esta dependencia y aceleración mutua se vuelve capaz de crear continuamente nuevos productos y servicios que modifican constantemente las formas de vida de individuos y colectivos.

Con la continua transformación de las ciencias, cambia constantemente la interpretación de la realidad, en todos sus niveles. El cambio de la interpretación altera la valoración.

Las transformaciones constantes de las tecnologías afectan directamente a las formas de trabajar y los modos de organización. A su vez, las modificaciones de las formas de organización y trabajo, traen consigo nuevos modos de la vida colectiva, que exigen nuevos sistemas de cohesión y de establecimiento de fines. 
En las sociedades de conocimiento e innovación continua, todos los parámetros de vida de los humanos cambian constante y aceleradamente.

A estos datos tendremos que añadir el fenómeno de la rápida globalización provocada por las mismas ciencias y tecnologías, por las comunicaciones, por los mercados de productos y financieros, por las grandes migraciones humanas dentro de un mismo país y entre países.

Esta globalización tiende a relativizar el valor pretendidamente absoluto de las culturas, de las religiones, de los valores y de las costumbres.

Tenemos pues que la necesidad de estar dispuestos a cambiar constantemente la interpretación y valoración de las realidades y los modos de vivir y organizarnos, junto al efecto relativizador de la globalización, conducen a una grave crisis axiológica a todos los pueblos.

Quienes tienen que vivir del cambio continuo en una sociedad globalizada, no pueden creer, porque las creencias tienen la función de fijar y hacer intocable un proyecto axiológico colectivo, teniéndolo como revelado por los dioses o los antepasados sagrados.

Los hombres y mujeres de las nuevas sociedades de conocimiento y, en menor medida aunque también real, los de las sociedades en tránsito rápido, no pueden creer porque tienen que vivir en las condiciones que les imponen las nuevas circunstancias culturales.

No pueden creer, no por su decadencia o maldad, sino por la lógica misma de las nuevas condiciones culturales. Debe quedar claro que no pueden creer, no es que no quieran.

Si no pueden creer, no pueden tener religión, ni pueden tener el Dios que proclaman las religiones. 
Las sociedades en rápido tránsito $y$, sobre todo las sociedades de conocimiento, innovación y cambio constante, sufren dos consecuencias de suma importancia: una transformación radical de la epistemología y de la antropología.

Las sociedades estáticas, que vivieron durante milenios haciendo fundamentalmente lo mismo, tenían una epistemología mítica que sostenía que lo que decían las narraciones sagradas, los mitos, los símbolos y los rituales, describían la realidad como es, tanto la profana, como la sagrada. Por consiguiente sus sistemas culturales eran y debían ser perennes.

$\mathrm{Su}$ antropología debía ser tan inmutable como su forma de vida y su epistemología. Según esa antropología, los humanos somos unos compuestos de cuerpo y espíritu. El cuerpo es el elemento mutable y perecedero, y el espíritu carece de mutaciones y es imperecedero.

Las sociedades de la primera industrialización eran sociedades pseudo estáticas, porque aunque cambiaban con frecuencia su ciencia y su tecnología, interpretaban que los fundamentos de la vida social, política, económica, las costumbres y los sistemas de organización eran estables porque venían determinados por la naturaleza misma de las cosas.

Continuaron con una epistemología mítica, porque aunque rechazaban las narraciones sagradas, los mitos y los símbolos como verdaderas descripciones de la realidad, sostenían que lo que verdaderamente describía el ser de la realidad eran las ciencias y las filosofías.

Su antropología se correspondía a su interpretación estática de la cultura: el hombre era un compuesto de animal y racionalidad. La animalidad era el elemento mutable y perecedero, pero la racionalidad era estable y perenne.

Las nuevas sociedades industriales de conocimiento, innovación y cambio tienen que modificar su epistemología. El crecimiento acelerado de las ciencias que cambian continuamente las formas de interpretar la realidad tiene que alejarse de 
la epistemología mítica.

La nueva epistemología tiene que sostener que las ciencias son modelaciones de la realidad, no descripciones de ella. Son un instrumento de un viviente para modelar el medio a su medida, como hacen todos los vivientes, para mejor poder sobrevivir en él. La nueva epistemología ya no es mítica, porque es consciente de que es construcción de modelos para tratar la realidad, que hoy son así, pero mañana pueden ser modificados, incluso radicalmente. Esta es la epistemología adecuada a una sociedad dinámica.

La antropología tendrá que ser también toda ella dinámica. Por el desarrollo mismo de las ciencias y de los modos continuamente cambiantes de interpretar y vivir, una antropología de cuerpo/espíritu es inadecuada y también lo es la sostiene que somos animales dotados de racionalidad.

La nueva antropología no tiene más remedio que sostener que somos unos vivientes que estamos constituidos como tales vivientes por el habla. Nuestra dotación genética no es suficiente para hacernos animales viables, pero la dotación genética misma nos proporcionó el habla, la competencia lingüística, como instrumento para completar, hablando entre nosotros, esa no completa determinación genética de nuestras maneras de vivir.

Gracias a ese formidable invento biológico, los humanos nos convertimos en unos vivientes sumamente flexibles porque podemos adaptarnos a los cambios del medio e incluso provocarlos, cuando convenga.

La flexibilidad con respecto al medio y a nuestra propia organización, como vivientes simbióticos, es nuestra diferencia específica.

Nuestra estructura de vivientes constituidos, como tales, por el habla nos proporciona un doble acceso a la realidad, que es la raíz de nuestra flexibilidad. Tenemos un acceso a la realidad como relativa a nuestras necesidades, como los 
restantes animales, y otro acceso no relativo a nuestra necesidad, y en ese sentido absoluto, gratuito.

Este doble acceso nos permite cambiar de modo de vida en el medio, incluso radicalmente, sin que tengamos que alterar para ello nuestra dotación fisiológica y genética. Los animales para cambiar su modo de vida tienen que cambiar su estructura fisiológica y genética, lo cual les lleva millones de años. Nosotros, por nuestro doble acceso a lo real sabemos en todo momento que una cosa es lo que las realidades significan para nosotros y otra lo que "eso de ahí, que nos incluye a nosotros mismos, es".

Podemos cambiar nuestra modelación de la realidad, su valoración, nuestra forma de actuación y nuestra organización cuando sea conveniente y como sea conveniente.

Este fenómeno exclusivamente humano de tener un doble acceso a la realidad, como veremos, es el fundamento teórico para una espiritualidad (cualidad humana honda) que no parta de creencias religiosas o de supuestos filosóficos, sino de datos, aunque sean unos datos peculiares.

El resumen de estas consideraciones es tener que entender que los animales, nuestros parientes, tienen un acceso simple a la realidad, determinado genéticamente e incambiable. Por lo cual, o cambian de especie, o no pueden hacer cambios.

Nosotros por el contrario, porque somos vivientes constituidos como tales por el habla, tenemos un acceso a la realidad bifurcado: un acceso relativo a nuestras necesidades y un acceso absoluto. Este doble acceso tiene varias consecuencias:

-nos permite modelar otro acceso relativo a lo real cuando es conveniente; 
-pone la gestión de nuestro destino como vivientes en nuestras manos, con los enormes riesgos que eso supone y que en las sociedades de conocimiento se han puesto agudamente de manifiesto;

-nos abre una portalón a la dimensión absoluta de lo real, por donde podemos entrar y navegar sin fin por ella. Las artes, las ciencias, las filosofías y las religiones y espiritualidades son prueba de ello.

Si no tuviéramos ese doble acceso a lo real, ni podríamos cambiar de modo de vida, ni de cultura, ni podríamos hacer arte o ciencia, ni podríamos haber creado las religiones, ni las espiritualidades.

Que existan estos fenómenos, exclusivamente humanos, prueba que la dimensión absoluta de lo real (DA) es un dato, una noticia, que aunque no se le reconozca como tal, es operativo.

Esta noticia, que por lo operativa que resulta, equivale a un dato, es el fundamento de la religión, de las espiritualidades orientales y es el fundamento también que abre a la posibilidad de una espiritualidad no religiosa a la nueva situación cultural.

Para mostrar lo que es una espiritualidad no religiosa, sin creencias y sin dioses bastaría con hacer una breve exposición del Yoga, del Budismo, del Vedanta Advaita. Todas estas son tradiciones no religiosas de una gran profundidad espiritual, que duraron milenios.

También en la tradición cristiana pueden encontrarse autores que proporcionen una base para una espiritualidad no religiosa, no apoyada en creencias y que puede presentarse sin teísmo, porque se apoya exclusivamente sobre la noticia de la dimensión absoluta de la realidad, aunque no se lo formulen así. 
Vamos a reflexionar sobre una noción sumamente importante de Nicolás de Cusa en su obra sobre el "no otro", "li non aliud" le llama él (NICOLAS, 2002).

\section{El "no otro" de toda realidad}

Hemos visto que, por nuestra condición de vivientes constituidos por el habla, la realidad se nos presenta siempre bifurcada en dos dimensiones, la relativa a nuestras necesidades y la absoluta.

No son dos realidades en paralelo, ni una realidad con dos pisos, son únicamente dos dimensiones de una única realidad. Significaremos la dimensión relativa con las siglas “DR” y a la dimensión absoluta con las siglas "DA".

Oscura o claramente tenemos noticia de que la DR está modelada a nuestra necesidad. En el pasado se pensó que esa modelación la hizo Dios, en la creación, o que es la naturaleza misma de las cosas. Esas eran las creencias de nuestros antepasados.

Tenemos noticia, oscura o claramente, pero siempre operativa, de que lo real es más que esa modelación a nuestra medida. Tenemos noticia explícita o implícita de que lo que hay ahí, esta inmensidad, existe independientemente de que tenga o no relación con nosotros los humanos.

Lo real, eso de ahí, es absoluto, en sentido de no relativo a nosotros. Esa es la noticia de la DA de lo real. Esa noticia no es un dato stricto sensu porque la dimensión absoluta no es relativa y al no ser relativa no es objetivable; lo que no es objetivable no es objeto de una experiencia en el sentido habitual del término. Sin embargo es una noticia clara y, lo que es importante, seria y continuamente operativa.

Todas las tradiciones religiosas y todas las tradiciones espirituales de la humanidad han sido plenamente conscientes de la peculiaridad de esa noticia y 
han afirmado que esa dimensión, la DA, -le hayan puesto el nombre que le hayan puesto, Dios, Vacío, Brahman, Tao-, es innombrable, inefable.

Aún conscientes de su naturaleza peculiar, esa noticia es de tal naturaleza, tan constante, $\tan$ universal y tan operativa en todos los niveles de la vida de nuestra especie, que podemos llamarle "dato".

La DR y la DA se presentan siempre, indefectiblemente juntas. Son el efecto de nuestro acceso bifurcado a todo lo real, consecuencia de nuestra estructura de vivientes, constituidos como tales por el habla. Nuestro doble acceso a lo real es consecuencia de nuestra estructura básica antropológica.

No es que vivamos dos niveles de realidades, sino una sola realidad a la que accedemos con una bifurcación. Gracias a esta peculiar estructura que nos permite un doble acceso a lo real, somos unos vivientes flexibles con relación al medio. La pretensión de esa nuestra estructura antropológica es de función biológica, no hay en ella ninguna pretensión religiosa, aunque, de hecho haya abierto la puerta y se haya convertido en el fundamento de las religiones y de las espiritualidades, como de otros muchos fenómenos humanos, como el arte, la ciencia, el amor desinteresado, etc.

No hay, pues acceso a una DR sin que se dé, se reconozca o no, simultáneamente un acceso a la DA; y no hay acceso posible a la DA sino es en el seno de la DR.

Podemos dejar como asentados dos hechos: el primero, la noticia de la DA, que tiene categoría de dato, y el segundo, que la DA no se presenta nunca fuera de la DR. Por nuestra condición de animales que por su condición de hablantes bifurcan su acceso a la realidad, la DR no puede presentarse nunca sin la DA y la DA no tiene ninguna posibilidad de aparecer a los humanos aislada, separada de concretas experiencias de DR. 
Por consiguiente, la DA no es fruto de una creencia, ni de un supuesto filosófico, sino que es una noticia que tiene la categoría de dato.

\subsection{La dimensión absoluta (DA) es la fuente de la dimensión relativa (DR)}

No hay experiencia ni dato objetivo en el que no se den esa dos dimensiones, DR y DA.

La DA puede estar explícita o sólo implícita, puede ser reconocida o no reconocida, pero está con toda la fuerza real operativa de la que ya hemos hablado. Cuando la DA no es sólo implícita y no reconocida, sino explícita y reconocida, la DA se presenta siempre, indefectiblemente, como fuente de la DR, jamás a la inversa.

No puede ser de otra manera porque nosotros, como todos los vivientes, modelamos la inmensidad que nos rodea a nuestra pequeña medida. Es lógico que "eso no modelado" aparezca como la fuente de la realidad de nuestra modelación. Nuestra modelación no puede aparecer como la fuente de "eso" sobre lo que se modela.

El viviente modelador del medio, el sujeto, también se presenta a sí mismo con las dos dimensiones. También en él la DA es la fuente de la DR, y no a la inversa.

Esto también es una noticia, un dato, no una creencia o un supuesto.

Por consiguiente, la DA es la fuente de toda modelación; y toda modelación es una delimitación, una acotación, una objetivación, una individualización de la DA.

No que la DA sea el actor de la modelación, el creador dicen las tradiciones religiosas, sino que modelando a través del viviente modelador, la DA se modela a sí misma. Nicolás de Cusa dice que la DA es el definidor (en el sentido de 
delimitador, de acotador, modelador) que todo lo define, y que, definiendo se define a sí mismo.

La DA, que es la fuente de la DR, que es la DA de la DR, modela la DR y modelándola, acotándola a través del humano, se modela a sí misma porque sólo se puede presentar a nosotros en el seno de la DR y como su fuente. Jamás puede presentarse a un viviente como nosotros más que en las cosas y experiencias que tienen que ver con nuestro sistema cerebral, sensitivo y activo, que siempre está en función de nuestras necesidades.

La DA, fuente de DR, ciñéndola, acotándola, se ciñe y se acota a sí misma porque se presenta a los humanos en los objetos, sujetos e individualidades que modela nuestra necesidad. No hay que pensar la DA como una entidad, porque lo que es una noticia, un dato para nosotros es que aparece como una dimensión de la bifurcación que origina nuestra estructura antropológica de vivientes constituidos por el habla.

Suponerle como una entidad frente a la DR es entrar en el terreno de la creencia. En las sociedades en tránsito y en las de conocimiento no podemos entrar en ese terreno, hemos de quedarnos en el ámbito de la noticia, de los datos. Sólo ahí puede fundamentarse una espiritualidad, una cualidad humana profunda no religiosa. Y lo interesante es que haciéndolo no nos separamos de los principios que proclama Nicolás de Cusa.

Puesto que la DR es fruto de la DA, y no a la inversa, toda acotación, toda individuación, toda objetivación no tiene otro punto de procedencia que no sea "eso que hay", la DA. El viviente, para sobrevivir, tiene que acotar, individualizar y objetivar, pero el viviente es sólo una forma de "eso que realmente es", por consiguiente, quien hace todas esas operaciones es, en realidad, la DA, la fuente. No es el viviente humano el que crea un mundo de sujetos y objetos, lo crea esa inmensidad de la que el humano no es más que una forma, una pequeña ola de ese mar. 
Las formas son formas de esa inmensidad, no algo añadido a ella. Las formas no añaden nada a esa inmensidad, son sólo olas de su mar. En palabras de Nicolás de Cusa, la DA es el "no otro" de toda realidad. Por tanto, toda objetivación, toda acotación, toda individuación no es "algo otro" de esa dimensión absoluta que es el "no otro" de todos y cada uno.

La DA como fuente última de toda modelación de "eso de ahí", no proyecta la modelación fuera de sí misma, como un Dios creador. La DR no puede ser proyectada fuera de la DA; reside en la DA y es la DA.

La DA, modelando, acotando e dividualizando, no modela, acota o individualiza algo fuera de sí, sino que se define, individualiza y acota a sí misma, porque ciñe su manifestación, si es que podemos emplear este lenguaje dual, a la DR accesible a los perceptores y el cerebro de los vivientes humanos. Ahí y sólo ahí se presenta.

No somos nadie venido a este mundo, ni el conjunto de los vivientes, ni tampoco los humanos; somos este mundo, somos formas de esa inmensidad. La inmensidad "no es otra" de las formas en que aparece, ni las formas que aparecen y desaparecen añaden o quitan nada a esa inmensidad.

De la DA, de esa inmensidad, procede toda acotación, modelación, individualización. Cuando lo hace no modela ni individualiza nada fuera de sí misma, sino que lo acotado e individualizado es la DA misma, sin que, por ello, desaparezca como tal DA en las acotaciones. Así ocurre con los humanos y su doble acceso bifurcado a lo real.

En todo sistema de modelación animal sólo hay la DA, aunque aparezca como sujetos, como objetos, como individualidades. Esa inmensidad, la DA es la individualizante y la individualizada. Sólo a los humanos se nos presenta con doble cara, a causa de nuestra estructura lingüística. Y lo que se presenta con doble cara, como Jano, no es otra cosa que la DA misma. 


\subsection{La DA es sin forma, pero se muestra en toda forma}

Toda forma es relativa a la modelación que hace un viviente. Si no hay seres vivientes, no hay modelaciones y, por consiguiente, no hay formas. La DA misma, en cuanto DA, es sin forma. Pero, a la vez, toda forma es forma del sin forma, es una modelación de Eso sin forma. Vale la afirmación budista: el Vacío (de toda forma) es forma, y toda forma es forma del Vacío. O dicho en términos vedantas: esto, las formas, es Aquello (el sin forma) y Aquello es esto.

Si eso es así, mires donde mires, sólo ves formas de Eso y sólo de Eso, sin nada añadido; y tú mismo eres Eso, dirían las Upanishad. Los musulmanes por su parte dicen: donde quiera que te gires, no verás más que la faz de Alá. No verás nada fuera de Alá, porque Alá es único y no tiene socios en el existir.

Por su parte Nicolás de Cusa diría que el ser, la realidad de toda individuación, de todo "otro" es el "no otro", la DA. Los "otros", las acotaciones, las individuaciones, no tienen entidad alguna si no es la del "no otro". Las objetivaciones, las individuaciones no tienen otra entidad más que la DA. El "no otro" de nada en concreto, porque no se liga a ningún "otro", es el ser de todo "otro".

Nada hay fuera de "Eso", la DA, ni siquiera con un ser como de sombra, o con un ser contingente, cuya realidad procede de otro (ens ab alio, criatura).

Todo tal cual es y viene, incluso si viene como las catastróficas modelaciones humanas a través de la historia, es la DA y sólo la DA.

Toques lo que toques, veas lo que veas, tocas y ves sólo formas del "sin forma". Fuera del "sin forma" no hay nada en las formas. Todos los sujetos y todos los objetos, todas las individuaciones son formas del "sin forma", son Eso absoluto y sólo Eso absoluto. 
Toda individualidad es suya, como su forma. Todo se asemeja a encarnaciones suyas. Por tanto, toda realidad es honda como el abismo.

Cuando un viviente modela, acota la realidad a la medida de su necesidad, en realidad lo hace la DA. El viviente modelador no es “otro" de la DA. Y la DA, esta inmensidad, "no es otra" del animal que modela y de sus modelaciones.

La DA no es la suma de todos los objetos, sujetos e individuaciones del tipo que sean. La inmensidad, la DA, tampoco es como un enorme contenedor que reúne en su seno todas las realidades diferenciadas. No es tampoco un productor de objetos, sujetos, indivualidades. No los conforma en su seno, ni fuera de él.

"Eso que es", la inmensidad, la DA, es el "no otro" de cada uno de los seres y de todo. Él es la modelación, la objetivación, la individualización de cada ser. Él, individualizando, acotando, objetivando, definiendo, se individualiza, se acota, se objetiviza, se define.

Nada es “otro" de Él, ni Él es “otro" de nada.

Todo viviente, incluidos los humanos, capta y vive lo real como un conjunto de "otros", de individuaciones, de acotaciones. La DA es el "no otro" de todas esas individuaciones y acotaciones. Nada existe que sea "otro" del "no otro".

Ya hemos dicho que la DA no se presenta fuera de DR a nosotros los humanos. Decir que existe antes y fuera de la DR en que se presenta, es hacerla “otro" de la DR, es hacerla "otro" de los sujetos, objetos e individuaciones. Si actuáramos así habría que creerlo o suponerlo. Eso no es lo que nos es dado.

Lo que nos es dado en toda captación de "otro" es que la DA, el "no otro" no es un dios, ni un principio "otro", se le conciba como se le conciba en el cosmos de la modelación humana.

Hay que comprender, hasta lo hondo, que "esto es Aquello y que Aquello es esto". 
"Eso", la DA, no se agota en ninguna forma, pero es inconcebible fuera de la forma. Afirmar otra cosa sería entrar en el ámbito de la creencia, cosa que nos está vedado.

El "no otro" de todo "otro" es el dato, la noticia sobre la que únicamente nos podemos apoyar para adentrarnos en la espiritualidad (en la cualidad humana profunda) en las nuevas sociedades industriales de conocimiento y también en las sociedades en tránsitos rápidos.

Hay que vigilar y afinar nuestros conceptos y representaciones para no alejarnos de lo que nos es dado y para no caer en las creencias o en los supuestos sin sólido fundamento. Nos va en ello la cualidad humana y la cualidad humana profunda (la espiritualidad) que tan imprescindible nos es para gestionar adecuadamente el potente aparato científico-técnico y los nuevos productos y servicios que de él se siguen.

Hay que afinar lo que entendemos por espiritualidad, si no queremos hacerla imposible para nuestros contemporáneos.

\subsection{Inseparabilidad de DR y DA}

Cuando una individualidad, un concreto "otro", un concreto DR desaparece, desaparece una presencia diferenciada de DA. Pero en realidad nada desaparece porque esa concreta individualidad, ese sujeto u objeto, no era "otro" del "no otro", no era entidad alguna fuera de la DA. Luego nada desaparece, cuando desaparece.

¿Qué entendemos, pues, por DA? Lo que aparece en cada uno de los elementos de DR. Así es como la DA viene; así es como es para nosotros los humanos. Y lo que es más grave, hay que asumir que la DA es "no otro" de cómo se nos presenta a los humanos. 
El "no otro", la DA, no tiene forma propia fuera de cómo se nos presenta. Entre el "otro" y el "no otro" no hay dualidad ninguna. La expresión de la DA como "no otro" de todo "otro" de Nicolás de Cusa es muy acertada porque nos dice que de todo "otro", la DA es su "no otro". Con esta manera de expresarse se elimina la posibilidad de pensar la DA como un “otro" respecto de todo “otro”. Así desparece de raíz toda posible dualidad.

La DA no puede pensarse correctamente, ateniéndose a la noticia que tenemos, como un Dios que es el absolutamente “otro" de todo "otro", de toda criatura. No es así como se nos presenta a los humanos la bifurcación de nuestro acceso a la realidad. No experimentamos dos realidades, sino una única realidad con dos dimensiones.

Por efecto del proyecto axiológico colectivo de las sociedades agrario autoritarias, el "no otro", la DA de toda realidad, ha sido representado, durante milenios, según los paradigmas de ese tipo de sociedades, como Dios, Señor y Creador de todo, por tanto, como el absolutamente “otro" de toda realidad. Así se vivió y, en muchas partes, todavía se vive, pero no son esos los datos. Esa es una interpretación jerárquica de los datos.

Cada una de nuestras individualidades desaparecerá sin dejar ni el polvo. También nuestra especie desaparecerá sin dejar ni rastro; y asé lo hará el cosmos entero.

La DA de nuestro existir y de todo existir es también el "no otro" de nuestro desaparecer. Así nos viene Eso. Todo es no siendo. Y en ese ser no siendo, se nos muestra la DA.

Surge una cuestión: cuando se produzca la gran implosión del cosmos, ¿desaparecerá con él la DA? Ciertamente desaparecerá la bifurcación del acceso a lo real propio y exclusivo de nuestra especie. Pero ¿desaparecerá eso absoluto?

Aunque la gran implosión no sea la ida a la nada absoluta, hasta ahí puede 
llegar nuestra mente, sin poder pasar más allá, so pena de entrar en el ámbito de la creencia. Después de la gran implosión, si es que se produce, ya no habrá más modelaciones, ni individuaciones, ya no habrá más datos y, por consiguiente, no habrá más bifurcación en el acceso a lo real. No habrá DA porque tampoco habrá DR.

\section{Consecuencias prácticas de estos conocimientos}

Sabemos que DA y DR son consecuencia de nuestro acceso bifurcado a la realidad, por nuestra condición de vivientes constituidos por el habla.

Sabemos también que entre estas dos dimensiones no hay dualidad alguna. No son dos realidades unidas, sino una única realidad con dos dimensiones.

Sabemos que la DA es la fuente de la DR y no a la inversa; que la DR no añade nada a DA. Que la DA define, acota a la DR y que definiendo y acotando, se define y se acota a ella misma.

Sabemos que la DA no se no aparece nunca fuera de la DR y que DR tampoco aparece nunca sin la DA, que puede presentarse explícita o implícitamente, pero siempre de forma operativa.

La consecuencia práctica de estos conocimientos, que son noticias com categoría de datos, es deshacer la identificación con la propia individualidad, como sujeto autónomo en un medio de objetos y sujetos, de individuaciones, en el que debe depredar para vivir.

Mi verdadera realidad no es mi individualidad que se identifica con el ego como paquete de deseos, temores, recuerdos y expectativas. Mi realidad es la DA que aquí, en mí, se individualiza, sin que sea la individualidad nada añadido a la DA. 
Si la DA es la fuente, es el "no otro" de mi individualidad, mi realidad no es el ego, que es mera función del cerebro al servicio de mi supervivencia; mi realidad es la del "no otro", la de la DA que aquí, en mí se acota y se define.

Expresado en otros términos: mi realidad no es la interpretación que hago de mí mismo como alguien venido a este mundo, identificado con mi ego, con mi personalidad, porque nadie ha venido a este mundo; mi realidad es esa inmensidad que todo es.

La definición, en sentido de acotación, la individualización de la DA en mí es un animal simbiótico depredador. La DA es el "no otro" de un animal depredador. Si soy consciente de que mi realidad es el "no otro", que es también la realidad de todo, mi depredación será con total respeto y veneración, desde el seno de la unidad completa y no desde el seno de la alteridad, ni menos desde la depredación inconsiderada.

Mi simbiosis con los demás humanos, con todos los vivientes del medio y con el medio mismo es conciencia de unidad, mi depredación se ha de realizar en el seno de esa misma conciencia de unidad.

Donde se actualice, donde se realice este conocer-sentir, la egocentración es imposible, porque se sabe que el ego como entidad autónoma es una ficción, un error necesario del viviente para poder depredar en el medio; y se sabe que sólo es una función del cerebro que, sin la ignorancia de creerse alguien, está al servicio de la sobrevivencia en simbiosis completa y en unidad con aquello mismo que debe depredar.

Este conocimiento y esta certeza interna generan una cualidad humana honda capaz de gestionar adecuadamente todas nuestras creaciones científicotécnicas, capaz de plantear convenientemente qué productos y qué servicios hay que proporcionar. Desde esta certeza interna se podrá saber cuál ha de ser el proyecto axiológico colectivo que, en cada estadio de desarrollo de nuestras tecnociencias y nuestros productos y servicios, habrá que construir y adoptar para 
que todo esté ordenado para generar la unidad en la simbiosis y la utilización del medio también en la más perfecta simbiosis.

La conciencia de que la realidad de todo humano es el "no otro", que es también la realidad de todo, evita de raíz la actitud egocentrada explotadora de personas y del medio, sin otra consideración que el propio provecho en el más corto plazo posible.

Esa conciencia evita igualmente concebir y organizar los grupos humanos como manadas de lobos, eficaces para la caza en beneficio de la manada, pero sin consideración por nada ni por nadie.

En todo lo afirmado no nos hemos apoyado en ninguna creencia, ni en ningún supuesto filosófico; sólo hay recogida de datos, y pensar sobre esos datos. Los datos que se refieren a la DA son más que datos en sentido estricto, son una noticia que es de tal naturaleza que resulta reconocible y operativa, con más fuerza que los datos objetivables, con relación a nuestra supervivencia de vivientes y a todos los niveles de la vida.

Ya hemos indicado que la DA no puede ser dato en sentido estricto porque es la dimensión sin forma de nuestro acceso a lo real, es la dimensión innombrable y, por tanto, inobjetivable y si no es objetivable no puede tener el sentido riguroso de dato. Sin embargo la noticia que tenemos de ella tiene la consistencia de un dato y más todavía porque es el fundamento de nuestra flexibilidad como especie; flexibilidad que nos convierte en los superdepredadores de la cadena trófica. Esa flexibilidad, fruto de nuestro acceso bifurcado a la realidad, es nuestra diferencia específica con relación a los restantes animales

Se ha procurado no especular o suponer algo más allá de los datos y se ha intentado plantear las consecuencias de esos datos. 


\subsection{El "no otro" después de la muerte}

La doble dimensión de lo real sólo es propia de los humanos. Sólo los humanos pueden hablar de la DA. Fuera del ámbito humano no tiene sentido hablar de DA y DR. Si nos ceñimos a los datos, no podemos hacer suposiciones más allá.

La DA sólo es para los que tienen DR, porque es una consecuencia de nuestro acceso a la realidad, como vivientes constituidos por la lengua. Por consiguiente, cuando un humano muere, cesa con él la DA. Nada queda de él después de la muerte que tenga acceso a una DA que se tendría que dar fuera de la DR. De eso no podemos saber nada; se saldría por completo de la noticia que tenemos.

Sin embargo la noticia que tenemos deja una incógnita abierta. Toda acotación, toda individualidad, tiene como fuente exclusiva, sin nada añadido, a la DA. Todo DR es una forma de la DA sin que, como DR añada nada a la DA. Eso significa que todo el ser de DR es DA. DR vivo es la DA y muerto también, porque fuera de DA no hay nada en DR. DR muerto seguirá siendo lo que siempre fue, DA.

Pero, sin embargo, ni DR permanece, ni DA seguirá siendo como algo frente a algún residuo de DR.

Intentado expresarlo de otra forma: No somos nadie venido a este mundo: no somos nadie cuando llegamos y no somos nadie cuando nos vamos. Somos esa inmensidad mientras duramos y cuando desaparecemos. Somos Eso y sólo Eso. Esa inmensidad no relativa a nosotros, absoluta como DA de nuestro vivir, cesa como tal con nuestro morir. Nada se altera y nada cesa, porque tampoco empezó, pero desaparece todo rastro de dualidad. De esa no dualidad no podemos decir palabra.

Cuando, según otra teoría del fin del universo, con la expansión del universo, las estrellas consuman su combustible y no haya más fenómenos en un universo apagado, frío y disperso, ¿qué pasa con la DA? 
En esa situación, no tiene ningún sentido hablar ni de DR ni de DA, por dos razones: primera, donde no hay fenómenos, no hay dato alguno; segunda, no habrá nadie para recibir o no recibir ese dato.

¿Hay DA, que es "como" mente, en sí? No tiene sentido hablar o plantearse esa cuestión.

\subsection{La DA no equivale a un Dios larvado}

Estas reflexiones excluyen el supuesto de una especie de Dios larvado, como una entidad detrás de todo proceso de nacimiento, desarrollo y muerte del cosmos. Lo que vale del cosmos, vale de los pueblos y vale de los individuos.

La DA es el dato inmediato, explícito o implícito, consciente o inconsciente, que los humanos tenemos por nuestra condición de vivientes constituidos por el habla. No podemos salirnos de ese dato, sin entrar en la creencia o en supuestos sin suficiente fundamento sólido.

La DA es una cuestión de noticia inmediata, de datos para los humanos. En el pasado ese dato se presentó como creencia por la necesidad ineludible de tener que vivirse en proyectos axiológicos colectivos jerárquicos, impositivos, de sumisión.

Las sociedades agrario-autoritarias, por ejemplo, que para sobrevivir tuvieron que formar grandes formaciones colectivas para que fueran capaces de controlar grandes ríos que posibilitaran el cultivo, que tenían que defender sus cosechas, que requerían crear una burocracia compleja, que tenían que construir grandes defensas, tuvieron que organizarse jerárquicamente.

El proyecto axiológico colectivo que tuvieron que construir debía motivar para la sumisión. La sumisión debía fundamentarse en algo radical, intocable. Eso les llevó a pensar que los mitos que construían y expresaban el PAC colectivo eran 
verdades y modos de vida absolutamente intocables. Esa intocabilidad expresaban y aseguraban las creencias.

En este contexto la DA se expresó como Señor, Dios, que imponía un modo de vida y un tipo de organización por sumisión.

Cuando esas modalidades de PAC, propias de sociedades agrarioautoritarias han muerto, porque ha desaparecido su forma de sobrevivir, es hora de rescatar limpios esos datos básicos y fundamentales para nuestra especie y su sistema de sobrevivencia.

Para indagar y expresar esa dimensión, se pueden afirmar muchas más cosas, pero entonces será entrando en el campo de las imágenes, como decir que es Uno, que es como un Dios, que es bueno, etc. Pero eso ya no son datos sino formaciones metalingüísticas que hablan sobre los datos.

Los datos son escuetamente, que hay una DR y una DA; que la DA es la fuente de DR; que "esto (la DR) es aquello (la DA)"; que "aquello (la DA) es esto (la DR); que sin DR no se presenta DA; que no hay DR sin DA; que la DA se presenta sin dualidad alguna.

Estas afirmaciones están justificadas como noticias, el resto son deducciones, indagaciones, formas de comunicar y expresar con imágenes.

\section{3 ¿Qué es, entonces, la espiritualidad?}

Desde esta perspectiva podemos fundamentar nuestra espiritualidad, nuestro acceso a la cualidad humana profunda, sobre la solidez de los datos, aunque sutiles, prescindiendo de supuestos filosóficos o creencias. Esto es de suma importancia para las sociedades de conocimiento.

La espiritualidad es reconocimiento de esas noticias hasta establecerse en ellas, lejos de la identificación con nuestro ego, como paquete, reunido al azar, de 
deseos y temores, recuerdos y expectativas, tomado como entidad venida a este mundo. Sólo eso es el camino de la espiritualidad, de la cualidad humana profunda, lo demás son sólo simbolizaciones religiosas dependientes de los PAC colectivos .

Podemos decir que sobre una base empírica, aunque con una empiría sutil, pero real y verificable, ni creída ni supuesta, podemos fundamentar la espiritualidad de las sociedades de conocimiento y también la espiritualidad de las sociedades en tránsito rápido.

Sobre esa misma base podemos fundamenta y abrir el acceso y el uso de los mundos simbólicos, que a lo largo de la historia han hablado de esa dimensión y han ideado procedimientos para cultivar y ahonda en el reconocimiento pleno de esa DA de nuestro acceso a lo real. Un reconocimiento tal que se convierta en el lugar de residencia de nuestro pensar, de nuestro sentir, de nuestra actuación y de todos los aspectos de nuestra vida individual y colectiva.

A partir del reconocimiento de esos datos tenemos acceso a todos los mundos simbólicos, sean religiosos o conceptuales. Desde ahí podemos usarlos con toda facilidad, sin tener que someternos a ningún sistema de creencias.

Todos los sistemas simbólicos, sean del tipo que sean y correspondan al modo de sobrevivencia que respondan, están abiertos para nosotros y a nuestra disposición para conseguir y ahondar en el reconocimiento de la DA.

En toda experiencia humana de la realidad está siempre presente, indefectiblemente, la noticia de la DA. Generalmente no se la reconoce explícitamente, pero siempre opera, tanto a nivel de especie, de los grupos humanos, de las culturas, como de los individuos. 


\subsection{El ser de mi individualidad y de mi identidad}

DA define, delimita, concreta, constituye en todo su ser a DR. Haciéndolo DA se delimita, concreta y en cierta manera se constituye a sí misma como dimensión de nuestro acceso absoluto a lo real.

Mi individualidad es un "otro", un sujeto y un objeto, cuya realidad es el "no otro" de ese "otro" que soy yo. La DA como "no otro" de mí es la realidad de mi individualidad. No se da ningún "otro" cuya realidad no sea el "no otro". Ese "no otro" no es "otro" respecto a mi individualidad; ni yo no soy "otro" respecto de ese "no otro". Hay que alejarse de la idea de que el "no otro", la DA, es como un Dios, absolutamente “otro" de mi, y que yo, soy una criatura “otra” de él, de la DA.

Luego lo que constituye la identidad de todo "otro" y la identidad de todo "otro" humano no es la necesidad, con el ego como vocero, ni es la peculiar forma de su estructura de deseos y temores, sus recuerdos y expectativas entendidas como su personalidad; lo que constituye su auténtica identidad es la DA que se delimita, se define, se acota en las formas de esa identidad, cruce de un sinfín de líneas que vienen de lejos y siguen lejos.

El ego, la personalidad sólo manifiesta esa identidad, no la constituye cuando erróneamente se toma por alguien venido a este mundo o cuando se interpreta correctamente sabiéndose nadie.

Luego la identidad de cada humano, mi propia identidad es la DA únicamente, sin nada añadido. Esto lo confirman todos los grandes del espíritu, sean musulmanes, budistas, vedantas, yoguis y también no pocos místicos cristianos.

Sabiduría es vivirse como DA, sin nada añadido; sabiduría es reconocer esa nuestra condición. 
Nicolás de Cusa llega a decir que la mejor forma de hablar de Dios es hablar del "no otro" de toda realidad. Consigue una forma muy afinada de expresar lo que es nuestra propia identidad y la identidad de toda realidad. Además da una gran pista de meditación.

Supuesto que mi individualidad y mi identidad, y la de todo "otro" es la DA y sólo la DA, en todo se ve la misma DA sin forma, pero constitutiva y constituyente de toda "otreidad".

¿Qué mejor fundamento para la simbiosis, la equidad, la justicia, la no sumisión, la libertad y la laicidad?

\section{Conclusión}

Desde el seno de la tradición cristiana, Nicolás de Cusa, con su noción de "non aliud", "no otro" nos proporciona una base sólida para construir una espiritualidad honda, ecuménica y sin creencias ni sumisiones; una espiritualidad no religiosa desde el mismo seno de la tradición religiosa cristiana.

Como hemos indicado en el inicio de este escrito, ni las sociedades en tránsito rápido de unas formas de sobrevivir a otras, ni menos las sociedades de conocimiento, innovación y cambio continuo, pueden someterse a un sistema de creencias religiosas que fijen la interpretación de la realidad, su valoración, los modos de actuar y de organizarse para cultivar la espiritualidad, que nosotros preferimos llamarle "cualidad humana profunda".

Las religiones, como sistemas intocables de creencias, resultan inasimilables para las nuevas sociedades que tienen que vivir de cambiar continuamente. La prueba de este hecho es que las generaciones más jóvenes abandonan, en su mayoría, silenciosamente y sin rebeldía, las religiones. 
El hecho, que creemos evidente, que las religiones, como las practicaron nuestros mayores, sean inviables, no significa que haya que dejarlas en las estanterías de la historia y olvidarlas. Las religiones son grandes depósitos de la sabiduría de nuestros antepasados. Una sabiduría indagada, corregida y afinada durante milenios.

En las nuevas sociedades, tanto las que están en tránsitos rápidos, como las sociedades de conocimiento, se necesita más que nunca la sabiduría para manejar adecuadamente el potente aparato científico-técnico en continuo crecimiento. No podemos pretender inventar esa sabiduría empezando desde cero, sería una gran necedad.

Se necesita, con urgencia, proporcionar espiritualidades no religiosas a los nuevos ciudadanos, que estén bien fundamentadas, que no pueden partir ni de creencias religiosas ni laicas y que, por tanto, tienen que fundamentarse en datos, aunque sean unos datos "sui generis".

Necesitamos también que esas espiritualidades no religiosas sean capaces de heredar todo el legado de las tradiciones religiosas y espirituales de toda la humanidad.

Necesitaremos, finalmente, procedimientos para hacer accesibles a todos los pueblos, a todas las civilizaciones y a todos los individuos humanos, esas fuentes de sabiduría del pasado en sus grandes textos y maestros, sin que eso suponga tener que creer lo que ellos creyeron, tener que pensar, sentir, actuar y organizarnos como ellos lo hicieron.

Esa habilidad ya hace tiempo que la adquirimos con el arte, ahora debemos extenderla a las obra y los autores de sabiduría del pasado. No es ni tiene por qué ser difícil.

Desde estas necesidades la aportación de Nicolás de Cusa con su noción del "no otro" es una gran aportación a nuestra tarea de construir espiritualidades no religiosas y sin creencias. 


\section{REFERENCIAS}

NICOLAS de Cues. Du non-outre. Le guide du penseur. Paris, Les éditions du cerf. 2002. CORBÍ, M. Religión sin religión. Madrid: PPC, 1996.

CORBI, M. Hacia una espiritualidad laica. Sin creencias, sin religiones, sin dioses, Barcelona, Ed. Herder, 2007, 350 p.

CORBÍ, M. Más allá de los límites: meditaciones sobre la unidad. Madrid:Bubok, 2009.

CORBÍ, M. El camino interior más allá de las formas religiosas. Barcelona:

Ediciones del Bronce, 1999. 